\title{
APLICABILIDADE DO CÓDIGO DE DEFESA DO CONSUMIDOR NAS LICITAÇÕES E CONTRATAÇÕES POR EMPRESAS PÚBLICAS
}

\author{
https://dx.doi.org/10.48097/2674-8673.2021n4p01
}

\author{
Wilzenberge Romão Correia da Silva ${ }^{1}$ \\ Carlos Augusto da Silva Cavalcanti ${ }^{2}$
}

\section{RESUMO}

O objetivo deste artigo é a análise da aplicabilidade do Código de Defesa do Consumidor nas licitações e contratações realizadas por empresas públicas, sob a ótica da Constituição Federal, em especial seu art. $173, \S 1^{\circ}$, II, do referido dispositivo infraconstitucional ora citado e da Lei Federal 13.303/2016, outrora denominada como "Lei das Estatais". Analisaremos se as empresas públicas podem inserir em seus instrumentos convocatórios as cláusulas que versem sobre o seu direito como consumidor final, se há alguma ofensa ao princípio do interesse público sobre o interesse privado com esta aplicação e se obedece aos princípios da legalidade e da vinculação ao instrumento convocatório.

Palavras-chave: Licitação. Contratação. Empresas públicas. CDC.

Data de submissão: 08/07/2020

Data de aprovação: 10/09/2020

\begin{abstract}
The purpose of this article is to analyze the applicability of the Consumer Protection Code on bidding and hiring carried out by public enterprises, from the perspective of the Federal Constitution, specially its art. 173, §1, II, of the aforementioned infraconstitutional provision and Federal Law 13.303 / 2016, formerly referred as the "State Companies Law". We will analyze if the public companies may insert in its convening instruments the clauses dealing with its right as final consumer, if there is any offense to the principle of public interest over private interest with this application and if it obeys to the principles of legality and binding to the convening instrument.
\end{abstract}

Keywords: Bidding. Hiring. Public enterprises. Consumer law.

1 Graduando do Curso de Direito da Faculdade Metropolitana da Grande Recife.

E-mail: berg_1984@hotmail.com

2 Orientador/Professor da Faculdade Metropolitana da Grande Recife.

E-mail: carloscavalcanti@metropolitana.edu.br 


\section{INTRODUÇÃO}

O presente projeto foi desenvolvido frente à aplicabilidade do Código de Defesa do Consumidor nas licitações e contratos das Empresas Públicas, uma vez que o Art. 173, $\S 1^{\circ}$, inciso II, da Constituição Federal, estabelece que estas estarão sujeitas ao regime jurídico próprio das empresas privadas, inclusive quanto aos direitos e obrigações civis, comerciais, etc., não recebendo também benefícios fiscais.

Este projeto de pesquisa tem como objetivo a análise da aplicabilidade do CDC nas licitações e contratações realizadas por empresas públicas. Sob a óptica da Constituição Federal, no referido dispositivo infraconstitucional ora citado, podemos compreender que as empresas públicas podem inserir em seus instrumentos convocatórios as cláusulas que versem sobre o seu direito como consumidor final.

O estudo em análise tem o objetivo de mitigar dúvidas sobre a aplicabilidade ou não do CDC nas licitações e contratações das empresas públicas. As empresas privadas fazem suas compras ou se utilizam de serviços com o emprego do Código de Defesa do Consumidor, já as empresas públicas norteiam-se por um instrumento de contratação com regras diferenciadas, de direito privado.

$\mathrm{O}$ art. $173, \S 1^{\circ}$ da $\mathrm{CF} / 88$ trouxe à baila o estatuto jurídico das empresas públicas, Lei $\mathrm{n}^{\mathrm{o}} 13.303 / 2016$, mais conhecida como "Lei das Estatais". Anterior ao referido estatuto, utilizavam-se da lei geral de licitações e contratações, $n^{\circ}$ 8.666/1993, até o dia 30 de junho de 2018, sendo esta data o prazo final para adequação das empresas públicas ao novo dispositivo legal.

\section{DA OFENSA AO PRINCÍPIO DA SUPREMACIA DO INTERESSE PÚBLICO SOBRE O PRIVADO}

Uma parte da doutrina pátria defende que a aplicabilidade do CDC nas licitações e contratações ofenderia o princípio da indisponibilidade da supremacia do interesse público sobre o privado, pois tal situação deixaria as empresas públicas em um estado de horizontalidade e não mais de verticalidade frente ao particular nas licitações e contratações promovidas por aquelas.

$\mathrm{O}$ art. 22, XXVII da CF/88 estabelece que as normas gerais de licitação e contratação das empresas públicas competem à união legislar. Foi isso o que fez com o advento da Lei $\mathrm{n}^{\mathrm{o}}$ 13.303/2016 (Lei das Estatais), dando a estas a oportunidade de estabelecer seus estatutos jurídicos de licitações, contratações e convênios, ou seja, delegando às referidas empresas a 
oportunidade de legislar sobre normas específicas de licitações e contratações, desde que não afronte a norma geral, qual seja, a Lei das Estatais, que serve de base para o estatuto das empresas.

Já o art. $173, \S 1^{\circ}$, inciso II da CF/88 estabelece que os estatutos jurídicos das empresas públicas disponham sobre: “[...] a sujeição ao regime jurídico próprio das empresas privadas, inclusive quanto aos direitos e obrigações civis, comerciais, trabalhistas e tributários [...]”"

Ora, se a própria $\mathrm{CF} / 88$ estabelece que as estatais devem ter sujeição ao regime jurídico próprio das empresas privadas como já exposto outrora, porque desse modo haveria ofensa ao princípio da indisponibilidade da supremacia do interesse público sobre o privado, com a horizontalidade entre as empresas públicas e os particulares?

O princípio da indisponibilidade e supremacia do interesse público sobre o privado é muito mais amplo, uma vez que este princípio pode ser aplicado à economicidade da licitação e à qualidade do serviço a serem prestados, e, aos princípios da administração pública legalidade, impessoalidade, moralidade, publicidade e eficiência, ou seja, a supremacia do interesse público sobre o privado deve estar presente em todos os atos administrativos para que assim o interesse público seja sempre preservado.

Neste sentido alertam os eminentes professores Dante e Cora: a primazia do interesse público sobre o privado coloca que os interesses da sociedade devem sobressair-se diante das necessidades específicas das pessoas. Portanto, na relação estabelecida entre a Administração Pública e um indivíduo, o interesse público deve prevalecer. Não se deve entender a efetividade do princípio em uma situação de mera satisfação de interesses ou conveniência dos agentes governamentais ou do ente estatal. Deve-se ir mais além, enxergando-o como um fator da estabilidade social. (BRITO \& COSTA, 2017).

Por todo o exposto, entende-se que não há de se falar em ofensa ao princípio da indisponibilidade da supremacia do interesse público sobre o particular, pois, como dito outrora, a supremacia do interesse público é mais ampla que uma mera relação entre a administração pública e a particular (que são considerados iguais) porque se opina que o interesse público está ligado a todos os princípios da administração, quais sejam: legalidade, impessoalidade, moralidade, publicidade e eficiência, ou seja, a aplicabilidade do Código de Defesa do Consumidor nas licitações e contratações não ofende nenhum destes princípios, pois, no caso das empresas públicas e sociedades de economia mista, estas cláusulas estariam explícitas no instrumento convocatório, obedecendo a um dos princípios da licitação: a vinculação a este instrumento. 
Destarte, não haveria ofensa ao princípio do interesse público sobre o privado, pois as cláusulas consumeristas estariam obedecendo aos princípios da Administração Pública: legalidade, em conformidade com o art. 173, §1, inciso II, que dispõe sobre a sujeição ao regime das empresas privadas, inclusive no que diz respeito aos direitos e obrigações civis; impessoalidade, já que as referidas cláusulas seriam aplicadas a todos os processos licitatórios, alcançando todos os interessados sem distinção; moralidade, pois estaria em obediência ao que rege o $\mathrm{CF} / 88$ e em conformidade com o instrumento convocatório; publicidade, uma vez que todos os editais de licitação são publicados e seriam com as referidas cláusulas para o máximo de alcance dos licitantes; e eficiência, pois os processos licitatórios não teriam tantos questionamentos.

\section{DA APLICAÇÃO DAS REGRAS CONSUMERISTAS NOS EDITAIS DE LICITAÇÕES}

Em uma análise de alguns instrumentos convocatórios de empresas públicas do nosso Estado, vimos que nenhum destes faz alusão às referidas regras de consumo. Acredita-se que estas deveriam constar, pois, em tais situações, as empresas públicas poderiam exigir de seus fornecedores a vinculação da garantia dos produtos ou serviços que forem adquiridos por meio do processo licitatório.

Com as devidas vênias a pensamentos contrários, é possível inferir que tais regras devem constar nos editais, consequentemente, as estatais estariam em obediência ao art. 173, $\S 1^{\circ}$, inciso II da Constituição Federal, sem falar no princípio da vinculação ao instrumento convocatório e da legalidade previsto no art. 31 caput da Lei ${ }^{\circ}$ 13.303/2016.

De acordo com Filho (2015, p. 248), são básicos os princípios da legalidade, da impessoalidade, da moralidade, da igualdade, da publicidade, da probidade administrativa, da vinculação ao instrumento convocatório e do julgamento objetivo, ou seja, tais princípios devem ser obedecidos sem restrições.

O Tribunal de Contas da União, tratando do tema sob a égide da Lei $\mathrm{n}^{0}$ 8.666/1993, exarou o Acórdão 1729/2008 - Plenário de relatoria do eminente ministro Valmir Campelo, em que defende que seja aplicada a regra de consumo à Administração Pública, por entender que a leitura do art. $2^{\circ}$ do CDC abrange as pessoas jurídicas, seja privada ou pública, in verbis: 
aplicável à Administração Pública enquanto consumidora de bens e serviços. Isso porque ao definir, em seu art. $2^{\circ}$, consumidor como toda pessoa física ou jurídica que adquire ou utiliza produto ou serviço como destinatário final, não fez nenhuma exceção, devendo, portanto, a Administração Pública se utilizar de todos os direitos ali estabelecidos, na condição de consumidora."

São vários os acórdãos e decisões do Tribunal de Contas da União que são a favor da aplicação do CDC na Administração Pública a exemplo do seguinte Acórdão 1.045/2000Plenário (Ata nº 48/2000) e da Decisão 634/96 - Plenário com outras decisões favoráveis à aplicabilidade do CDC nas licitações da Administração. Todos coadunam o entendimento aqui exposto de que pode ser aplicado o CDC nas licitações públicas. Ora, se o TCU entendeu sob a égide da Lei $n^{\circ}$ 8.666/93 que poderia ser aplicado o $\mathrm{CDC}$, por que não o utilizar o Código de Defesa do Consumidor nas licitações e contratações das estatais sob o esteio da Lei $13.303 / 2016 ?$

Todavia, observa-se que nos Acórdãos supracitados, a Côrte de Contas não exige que tais cláusulas estejam nos editais de licitação para que haja a vinculação ao instrumento convocatório, princípio basilar das licitações públicas. Discordando dos acórdãos neste sentido, entende-se que não pode ser aplicado nada nos contratos que não estejam nos respectivos editais, pois, se houver aplicação de cláusulas que não estejam nos editais, nos contratos de aquisição ou prestação de serviços, o procedimento de licitação seria inválido.

Conforme as palavras de Filho (2015, p. 250):

A vinculação ao instrumento convocatório é garantia do administrador e dos administrados. Significa que as regras traçadas para o procedimento devem ser fielmente observadas por todos. Se a regra fixada não é respeitada, o procedimento se torna inválido e suscetível de correção na via administrativa ou judicial.

Aplicando-se as regras de consumo nos editais, as empresas públicas poderiam exigir dos fornecedores ou prestadores uma garantia maior, pois estes só estão ligados às empresas estatais até o fim do prazo de vigência dos contratos, ou seja, as empresas públicas estariam mais seguras, mesmo que seja um contrato de curta duração. E o mais importante: sem gastos adicionais para as empresas públicas.

\section{CONCLUSÃO}

Por todo o exposto conclui-se que a utilização do Código de Defesa do Consumidor nas licitações e contratações nas empresas estatais deve ser plenamente aplicada, para que seja cumprido o princípio da legalidade inerente à Administração Pública em geral, vez que as 
empresas estatais são pessoas jurídicas de direito público integrantes da Administração Indireta e fazem parte do Estado.

Ora, se o legislador infraconstitucional dispôs no art. $2^{\circ}$ do CDC que consumidor é toda pessoa física ou jurídica, entende-se que deve ser utilizado em favor das estatais as cláusulas de consumo para a proteção destas empresas, como dispõe o art. 68 da lei 13.303/2016, em que os contratos serão regidos pelo disposto na lei, em suas cláusulas, e pelos preceitos do direito privado, ou seja, cabe a aplicação do disposto no Código de Defesa do Consumidor para estatais, sendo estas consideradas como vulneráveis nesta relação de consumo.

Mas, para que os contratos venham a receber estas cláusulas de consumo, devem estar também nos editais para assim prevalecer o princípio da vinculação ao instrumento convocatório não ocorrendo nenhuma modificação ulterior e serem pegos de surpresa, tanto o administrador quanto o administrado.

\section{REFERÊNCIAS}

BRASIL. Lei $n^{\circ}$ 8.078, de 11 de setembro de 1991. Código de Defesa do Consumidor. Vade Mecum. Legislação Específica Administrativo e Constitucional, MAZZA Alexandre, 21. edição, 2019.

BRASIL. Constituição da República Federativa do Brasil. 05 de outubro de 1988. Disponível em: http://www.planalto.gov.br/ccivil_03/constituicao/constituicao.htm. Acesso em: 23 mar. 2020.

BRASIL. Lei $\mathrm{n}^{0}$ 13.303, de 30 de junho de 2016. Lei das Estatais. Disponível em: http://www.planalto.gov.br/ccivil_03/_ato2015-2018/2016/1ei/113303.htm. Acesso em: 12 abr. 2020.

BRITO, Dante Ponte de; COSTA, Cora Cristina Ramos Barros. Contratos administrativos e aplicabilidade das normas consumeristas. Revista Eletrônica Arquivo Jurídico - ISSN 2317-918X - Teresina-PI - v. 4 - n. 1 - p. 55-83, Jan./Jul. de 2017.

FILHO, José dos Santos Carvalho. Manual de Direito Administrativo. 28. ed. São Paulo: Atlas 2015. 